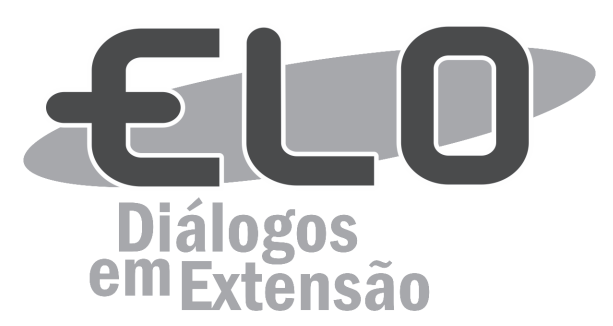

\title{
Ação Civico-Social (ACiSo): A experiência de estudantes universitários participantes do Projeto Rondon na Ilha do Marajó, Estado do Pará
}

Eunice Ferreira da Silva1 , Valdomiro Lourenço Nachornik ${ }^{2}$

\begin{abstract}
Resumo: Este artigo é um relato da experiência vivenciada por estudantes universitários da área de saúde, integrantes do Projeto Rondon, que participaram de ações cívico-sociais em comunidades ribeirinhas isoladas da Ilha do Marajó (Pará) com a equipe de saúde do Hospital Naval de Belém, pertencente à Marinha do Brasil. A expedição ocorreu entre os dias 19 e 28 de julho de 2014, na região do município de Portel. As ACiSo's objetivam prestar assistência a populações desassistidas, em comunidades de difícil acesso e precárias condições de saúde.
\end{abstract}

Palavras-chave: Extensão universitária. Saúde pública. Marinha do Brasil. Projeto Rondon.

Área Temática: Saúde e Educação.

Civic and Social Action (ACiSo): The experience of college students participating in the Rondon Project in Marajó Island, Pará

Abstract: This article reports an experience of university healthcare students, members of the Rondon Project, who participated in civic and social activities in isolated coastal communities in Marajó Island (Pará) along with the health team of the Naval Hospital of Belém, belonging the Navy of Brazil. The expedition took place between June 19 and July 28, 2014, in Portel county region. The ACiSo's aim to assist underserved populations in inaccessible and poor heal th communities.

Keywords: University extension. Public health. Navy of Brazil. Rondon Project.

Thematic area: Healthe Education.

\section{Civico y Social Acción (ACiSo): La experiencia de los estudiantes universitarios que participan en el Proyecto Rondón en la isla de Marajó, Pará}

Resumen: Este artículo presenta una experiencia de los estudiantes universitarios de la salud, miembros del Proyecto Rondón, que participaron en las actividades cívicas y sociales en las comunidades costeras aisladas en la Isla de Marajó (Pará), junto con el equipo de salud del Hospital Naval de Belém, que pertenece la Marina de Brasil. La expedición tuvo lugar entre el 19 de junio y 28 de julio de 2014, en la región del condado Portel. El objetivo de la ACiSo para ayudar a las poblaciones marginadas en las comunidades de salud inaccesibles y pobres.

Palabras clave: Extensión universitária. Salud pública. Marina de Brasil. Proyecto Rondón.

Áreas Temática: Salud, Educación.

\footnotetext{
${ }^{1}$ Acadêmica do curso de graduação em Enfermagem da Universidade Federal de Viçosa (UFV) / MG. Endereço para correspondência: Eunice Ferreira da Silva. Universidade Federal de Viçosa, Centro de Ciências Biológicas e da Saúde, Departamento de Medicina e Enfermagem. Campus Universitário. Av. P. H. Rolfs, s/ n. Centro. Viçosa/MG. Brasil. CEP 36570-000. Telefone: (31)3899-3936. Correio eletrônico: eunice.f.silva@ufv.br

${ }^{2}$ Orientador. Professor adjunto da Universidade Tuiuti do Paraná (UTP) / PR.
} 


\section{Introdução}

O Projeto Rondon é uma ação do Governo Federal, coordenada pelo Ministério da Defesa (MD), com o propósito de capacitar agentes multiplicadores em municípios isolados e carentes do Brasil e proporcionar o contato de futuros profissionais com uma realidade distinta daquela encontrada nos grandes centros urbanos, oferecendo crescimento pessoal e fortalecimento da cidadania (MARINHA DO BRASIL, 2014a).

Os objetivos das atividades denominadas "Ações Cívico-Sociais" (ACiSo), realizadas pela Marinha do Brasil em conjunto com o Projeto Rondon, são prestar assistência médico-odontológica às comunidades ribeirinhas de difícil acesso e precárias condições de saúde; cooperar com as comunidades na solução de seus problemas mais prementes e promover o fortalecimento dos padrões cívicos e do espírito comunitário dos cidadãos, aproveitando os recursos em pessoal, material e técnicos disponíveis. No caso específico da ACiSo de julho de 2014, as populações-alvo estão localizadas entre os municípios de Melgaço e Portel, na mesorregião do Marajó no Estado do Pará.

O Arquipélago do Marajó, o maior do mundo, é formado por um conjunto de ilhas de origem fluviomarinho (BRASIL, 2007; FUNDO VALE, 2011), que ocupam uma área de $49.606 \mathrm{Km}^{2}$, situadas integralmente no Estado do Pará (PA) (BRASIL, 2007). O município de Portel é o maior nessa localidade e, segundo dados de 2010 do Instituto Brasileiro de Geografia e Estatística (IBGE), tem uma população de 52.172 habitantes com uma densidade demográfica de 2,06 hab $/ \mathrm{Km}^{2}$. O Índice de Desenvolvimento Humano (IDH) é de 0,483 (IBGE, 2010). São inúmeras as comunidades ribeirinhas que vivem na região. O biótipo da população no geral é uma mescla do caboclo com o indígena. A cor da pele predominante é parda. A economia na região é essencialmente primária, baseando-se no extrativismo vegetal, na pesca, na pecuária extensiva e na agricultura de subsistência. O Produto Interno Bruto (PIB) da mesorregião é baixo (24\% do PIB per capita médio do País) e nas áreas urbanas o comércio e a indústria são incipientes, exemplificados pelo beneficiamento de riquezas regionais, como a madeireira (BRASIL, 2007). O clima regional é o tropical com duas estações distintas: o verão (agosto a dezembro) caracterizado pela diminuição das chuvas e aumento da temperatura e o inverno (janeiro a julho) com alta pluviosidade, responsável pela cheia dos rios. A diferença de temperatura é mínima entre as duas estações. Na região de atividades da ACiSo os rios apresentam pequenas variações no volume em razão das marés que adentram por dezenas de quilômetros pelo arquipélago. A ACiSo ocorreu na transição do inverno para o verão regional, ainda na vazante dos rios. O sol, em virtude da localização praticamente na linha do Equador da Terra, situa-se a pino ao meio dia nascendo muito cedo e se pondo por volta das 18 horas ou mais.

Em relação à saúde, a região apresenta uma infraestrutura insuficiente na área urbana e praticamente inexistente na rural, não havendo a efetivação plena do direito ao serviço público de saúde no Marajó (FUNDO VALE, 2011). Há um baixo número de médicos, enfermeiros e dentistas. Os poucos profissionais de saúde existentes trabalham na Capital e nas grandes cidades do Estado. Além disso, há um isolamento das comunidades rurais com a falta de transporte para locomoção de doentes até as cidades uma vez que não existem estradas (FUNDO VALE, 2011), sendo o transporte aquaviário dominante (BRASIL, 2007). Além disso, não há valorização do Agente Comunitário de Saúde (ACS) e os serviços prestados, em relação a medicamentos, são de má qualidade (FUNDO VALE, 2011). Observa-se uma falta apoio mais substancial às políticas de combate à malária (FUNDO VALE, 2011; BRASIL, 2007), doenças sexualmente transmissíveis (DST) e outras doenças. A disponibilidade de leitos hospitalares está abaixo das necessidades da população ou inexistem em alguns municípios marajoaras. As taxas de mortalidade materna e infantil são elevadas, há baixa cobertura vacinal e pouca oferta de serviços do Sistema Único de Saúde (SUS). É também preocupante o alto índice de gravidez na adolescência (FUNDO VALE, 2011).

As doenças mais frequentes são a malária, as infecções intestinais, a cólera, as hepatites decorrentes da má qualidade da água e a doença de Chagas (BRASIL, 2007). As picadas de cobra são bastante comuns e representam 7 em cada 10 pedidos de transporte das comunidades rurais para a emergência. Ainda é recorrente o escalpelamento feminino, acidente causado pelo enrolamento do cabelo no eixo de hélices sem proteção, sobretudo nas pequenas embarcações, causando graves lesões.

Como agravantes, tem-se a baixa qualidade da água consumida pela população e a ausência do serviço de esgotamento sanitário (BRASIL, 2007). O acúmulo de resíduos sólidos urbanos (lançados em lixões a céu aberto na maioria dos municípios) favorece a reprodução dos mosquitos da dengue e a malária e colabora para a disseminação de outras doenças. Na periferia de algumas cidades e nas 
comunidades ribeirinhas, a água para consumo humano não passa por qualquer tratamento e a população consome a água retirada diretamente dos rios. Muitas comunidades estão situadas em igarapés, dos quais se extrai a água e o peixe para consumo e, com a inexistência de sistema de coleta de esgotos (lançado no corpo hídrico sem tratamento), a população consome água e peixes contaminados.

Em relação à educação há uma grande deficiência em atender a clientela residente nas áreas rurais (BRASIL, 2007). É grande o número de alunos (próximo de 60\%) com defasagem na relação idade-série recomendada pelo Ministério da Educação. Entre o ensino fundamental e o médio há grande evasão de estudantes, sendo poucos aqueles que chegam ao ensino superior, também por causa da dificuldade de locomoção. A ausência de um sistema educacional de qualidade na região gera um círculo vicioso de analfabetismo absoluto e funcional que, consequentemente, influencia na formação de tomadores de decisões entre os marajoaras (FUNDO VALE, 2011).

\section{Metodologia}

Trata-se de um relato de experiência da participação na ação cívico-social (ACiSo) ocorrida entre os dias 19 e 28 de julho de 2014, em comunidades ribeirinhas da mesorregião do Marajó, Estado do Pará, mais especificamente em parte do Arquipélago do Marajó. As ações foram coordenadas pela Marinha do Brasil. Participaram da operação 21 integrantes do Projeto Rondon, grupo esse constituído por 3 docentes e 18 discentes de diversos cursos de graduação da área de saúde, representando 18 Instituições de Ensino Superior (IES), públicas e particulares, de 12 estados do país. Os atendimentos se davam da seguinte forma: triagem; verificação da pressão sanguínea, glicemia e temperatura; encaminhamento para odontologia, medicina e saúde da mulher; consulta médica e/ou odontológica com apoio diagnóstico e farmacêutico. Uma equipe de profissionais de saúde do Hospital Naval de Belém (HNBe) acompanhava os rondonistas no atendimento à população.

\section{Descrição da expedição e resultados das atividades}

Os rondonistas partiram de suas cidades de origem com destino a Belém, no Pará, no dia 18 de julho de 2014. Os docentes e acadêmicos foram recepcionados, no dia 19, no Aeroporto Internacional de Belém por um oficial, representante da Marinha do Brasil. Foram então conduzidos até a Base Naval de Val de Cães, onde se encontrava aportado o Navio-Auxiliar (NA) "Pará", o alojamento dos rondonistas durante 12 dias. Os rondonistas foram distribuídos nas cabines do navio, em beliches ou treliches, e receberam uma singela lembrança (4 bombons com sabores típicos do Pará em uma embalagem artesanal), acompanhados de um cartão desejando sucesso a todos naquela "jornada cívica". Os camarotes eram bem pequenos e a água para o banho, fria, mas o entusiasmo da equipe era enorme e superava qualquer tipo de desconforto.

Ainda na noite do dia 19, ocorreu uma inesquecível recepção a bordo do Navio-Veleiro "Cisne Branco", que se encontrava aportado na Estação das Docas. Após 6 meses de viagem contornando a América do Sul, essa embarcação aportava, pela primeira vez, em um porto brasileiro. O Cisne Branco é um navio construído nos moldes dos veleiros antigos, sendo considerado o navio mais belo da frota da Marinha brasileira, o qual os rondonistas tiveram a honra de conhecer.

O NA "Pará" suspendeu no dia 20 de julho³, às 11h, em uma viagem com duração de 27 horas, rumo ao Marajó. A população a bordo contava com cerca de 170 pessoas, incluindo a tripulação (marinheiros e fuzileiros navais), a equipe de saúde do HNBe (médicos clínicos e patologista, dentistas, farmacêuticos, enfermeira, técnicos em enfermagem, técnicos em radiologia e de laboratório), os rondonistas, os agentes do INSS, integrantes da Capitania dos Portos e outros convidados e voluntários, como a médica responsável pela liberação dos laudos das mamografias.

Os agentes do INSS levaram atendimento previdenciário aos ribeirinhos. Já a equipe da Capitania dos Portos, da Amazônia Oriental, realizou atividades envolvendo patrulha e inspeção naval, visando à segurança da navegação. Foram também oferecidos Cursos de Formação para Aquaviários, bem como a instalação gratuita de coberturas de eixos nas embarcações, para evitar os acidentes por escalpelamento (MARINHA DO BRASIL, 2014a).

A equipe dos rondonistas foi composta por 3 professores e 18 estudantes universitários, todos da área de saúde, sendo 5 do curso de enfermagem, 5 de odontologia, 4 de medicina, 2 de farmácia, 1 de nutrição e 1 de fisioterapia. 
No dia 21 de julho, foram distribuídos donativos em algumas comunidades localizadas às margens do estreito de Boiuçu, durante o trânsito para a Área de Operações do Projeto Rondon. Os donativos foram provenientes de mobilizações promovidas pela assistência religiosa do Comando do $4^{\circ}$ Distrito Naval antes da viagem, para a arrecadação dos itens a serem doados (MARINHA DO BRASIL, 2014c). Após 27 horas de viagem, o NA fundeou na Baia de Portel às 14h, iniciando-se o atendimento aos ribeirinhos às $17 \mathrm{~h}$, a bordo. As embarcações, na maioria "rabetinhas" e "po pó pós", aproximavamse do navio e as pessoas eram conduzidas para o Convés do Toldo, onde as orientações e os atendimentos eram iniciados. Esses atendimentos estenderam-se até as $18 \mathrm{~h} 30 \mathrm{~m}$ nesse primeiro dia.

A partir de terça-feira, 22 de julho, as equipes foram divididas para maximizar o atendimento à população. Uma equipe itinerante foi destacada para atendimento em terra em uma comunidade mais distante. Metade dos rondonistas mantinha o atendimento no navio, com parte da equipe de saúde da marinha. Os participantes revezavam-se diariamente nessas incumbências. A equipe itinerante partiu em várias Embarcações de Transporte de Tropas (ETT) para visitar a primeira comunidade ribeirinha: a Comunidade de Santo Agostinho, na baía de mesmo nome, próximo ao local onde o navio encontrava-se fundeado. Houve um grande predomínio de mulheres e crianças nos atendimentos, pois os jovens e adultos do sexo masculino encontravam-se nas atividades laborais cotidianas. Também foram encontrados poucos idosos nessas comunidades. Na Comunidade de Santo Agostinho existe um ACS. Ao final da tarde foi realizada uma missa pelo padre, capelão da Marinha, na mesma igreja palco dos atendimentos. As missas oficiais, realizadas por um padre ou capelão acontecem uma vez ao ano na comunidade, mas os ribeirinhos reúnem-se semanalmente, aos domingos, na Igreja para uma atividade religiosa.

Na quarta-feira, dia 23 de julho, navegando pelo Rio Pacajá, o navio continuou os atendimentos e a equipe itinerante partiu para atendimento em terra na Comunidade de Cocal (figura 1), onde existe um pequeno Posto de Saúde, porém não há nenhum profissional de saúde para os atendimentos. O NA "Pará" fundeou em frente à comunidade. À tarde a equipe de bordo "rendeu" a equipe de terra para que pudessem almoçar a bordo do navio.

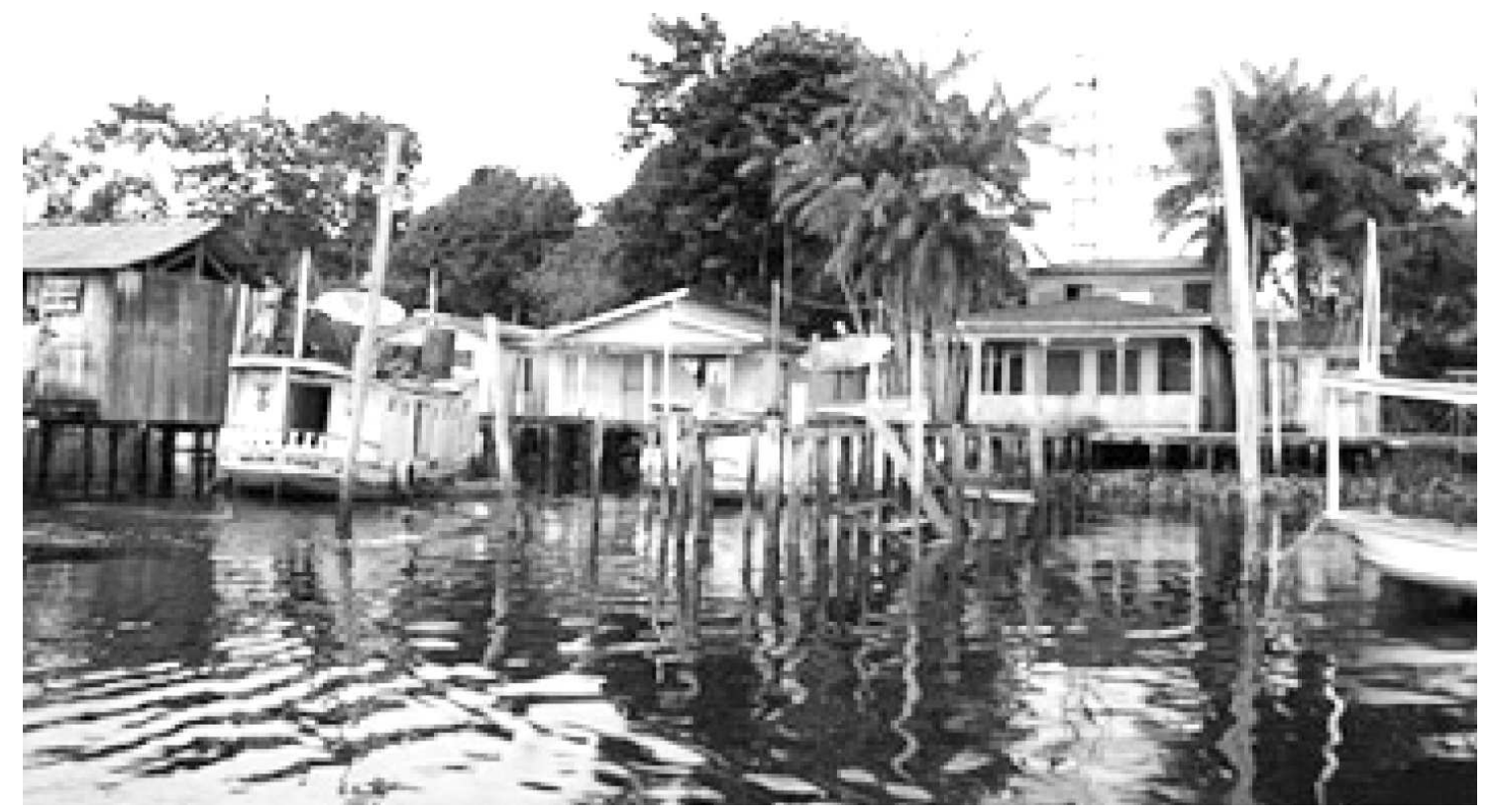

Figura 1 - Comunidade de Cocal

Foto: Eunice Ferreira da Silva

No dia 24 de julho, quinta-feira, a equipe itinerante partiu para a Comunidade de Menino Deus, no Rio Anapu, na embarcação denominada AviPa (Aviso de Patrulhamento) "Tucunaré", a qual, por ser maior, comportava a todos. A comunidade encontrava-se a cerca de 10 milhas do local onde o NA "Pará" permaneceu fundeado, levando 1h40m para chegar ao seu destino. Nessa comunidade, o atendimento ocorreu em um galpão, o qual também funciona como uma escola multisseriada. Na comunidade também existem uma Igreja e uma creche com um pequena biblioteca, muito organizadas pela professora local. Nessa comunidade pode-se conhecer o processo de fabricação da farinha d'água 
e acompanhar a reforma de um barco com madeira de maçaranduba. Por ocasião, ocorreu a reportagem da TV Liberal, afiliada da Rede Globo no Pará, que estava acompanhando principalmente a realização das mamografias. A reportagem foi ao ar na segunda-feira, dia 28, no Programa "Bom Dia Brasil" ", na Globo News e Globo Internacional e, posteriormente, em outubro, no Programa "Como Será?" ${ }^{5}$. Nesse dia também foi realizada uma missa no final da tarde.

Já na sexta-feira, 25 de julho, o atendimento ocorreu em uma comunidade distante, cerca de 23 milhas do navio (cerca de 70 quilômetros de Portel), denominada Acangatá (figura 2), localizada no Rio Camaraipi. Nessa localidade, a equipe do HNBe e integrantes do Projeto Rondon realizaram atendimento médico e odontológico, além de assistência religiosa e ações de patrulha e inspeção naval visando incrementar a segurança da navegação naquela localidade (MARINHA DO BRASIL, 2014b). A viagem, na AViPa, durou cerca de $3 \mathrm{~h}$. Todos os dias, as itinerantes partiam cerca de $6 \mathrm{~h} 30 \mathrm{~m}$ da manhã, nesse dia, porém, em razão da distância, partiram ainda mais cedo e retornaram somente por volta das $20 \mathrm{~h}$.

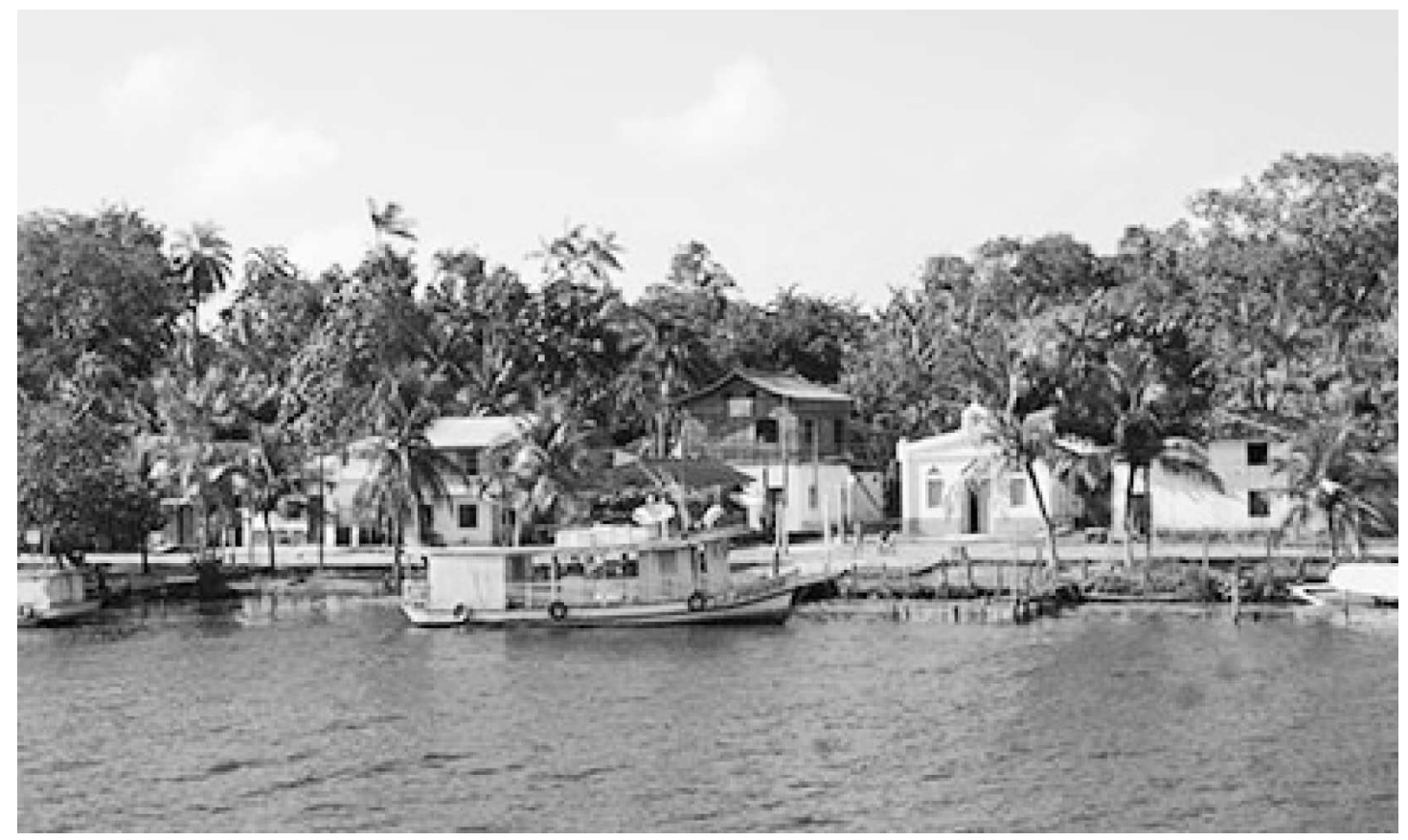

Figura 2 - Comunidade de Acangatá

Foto: Valdomiro Lourenço Nachornik

No sábado, dia 26 de julho e no domingo, dia 27, o atendimento foi grande, ocorrendo exclusivamente a bordo do Navio, o qual abarrancou na cidade de Portel, atendendo ao município e adjacências, pois se observou o deslocamento de ribeirinhos de comunidades relativamente distantes para receber atendimento. Os trabalhos ocorreram das $7 \mathrm{~h}$ às 18 horas no sábado e das $10 \mathrm{~h}$ às $16 \mathrm{~h}$ no domingo em razão da grande demanda, embora, inicialmente, estivesse previsto apenas equipe mínima para esse dia.

No dia 28 de julho, segunda-feira, a comunidade atendida foi a de Antônio Lemos (figura 3), no Furo do Tajapuru ("furo" é uma comunicação natural entre dois rios ou entre um rio e uma lagoa).

Os atendimentos, tanto a bordo do navio quanto em terra, aconteciam da seguinte maneira: Alguns rondonistas acolhiam os ribeirinhos e realizavam a triagem, quer seja a bordo do NA Pará ou em terra, com uma pequena anamnese, aferição da pressão arterial e, caso necessário, verificação da glicemia capilar e temperatura corporal. Após o acolhimento, o paciente era conduzido ao respectivo setor para atendimento, quer seja consulta médica ou odontológica, realização do exame citopatológico (preventivo) com a enfermeira ou mamografia. Outros rondonistas, acadêmicos de medicina e odontologia, os quais se encontravam mais avançados em seus cursos de graduação, e os profissionais de saúde da Marinha (médicos e dentistas) participavam diretamente do atendimento, realizando as consultas, os procedimentos e a solicitação dos exames necessários. Os rondonistas em atendimento encontravam-se permanentemente sob a supervisão dos profissionais da Marinha. Os ribeirinhos em 
terra, caso necessitassem de algum procedimento, exame ou cuidado mais específico, como um curativo ou uma sutura, eram encaminhados para bordo do navio através das ETT, acompanhados pela equipe de apoio, representada pelos fuzileiros navais. A coleta de material e os exames (laboratoriais, mamografia ou preventivo) eram realizados nos laboratórios do próprio navio. Os laudos das mamografias eram elaborados pela médica radiologista voluntária. Os ribeirinhos aguardavam pelos exames por, aproximadamente 1 hora e, enquanto isso, participavam de outras atividades. A consulta de retorno era realizada assim que o resultado do exame solicitado estivesse concluído. Muitos casos clínicos, mais simples, eram solucionados através de procedimentos odontológicos (restaurações, extrações e limpezas dentárias) e consultas médicas, com a prescrição e distribuição gratuita e imediata de medicamentos da farmácia do navio ou da equipe itinerante em terra, realizadas pelas rondonistas, acadêmicas de farmácia, sob a supervisão de uma farmacêutica da equipe do HNBe. Casos de média complexidade eram encaminhados para Portel, a cidade de referência da região abrangida, e, se houvesse a necessidade de notificação compulsória, os ribeirinhos dessas comunidades eram notificados para a Vigilância Epidemiológica de Portel. Os casos mais complexos eram encaminhados para Belém.

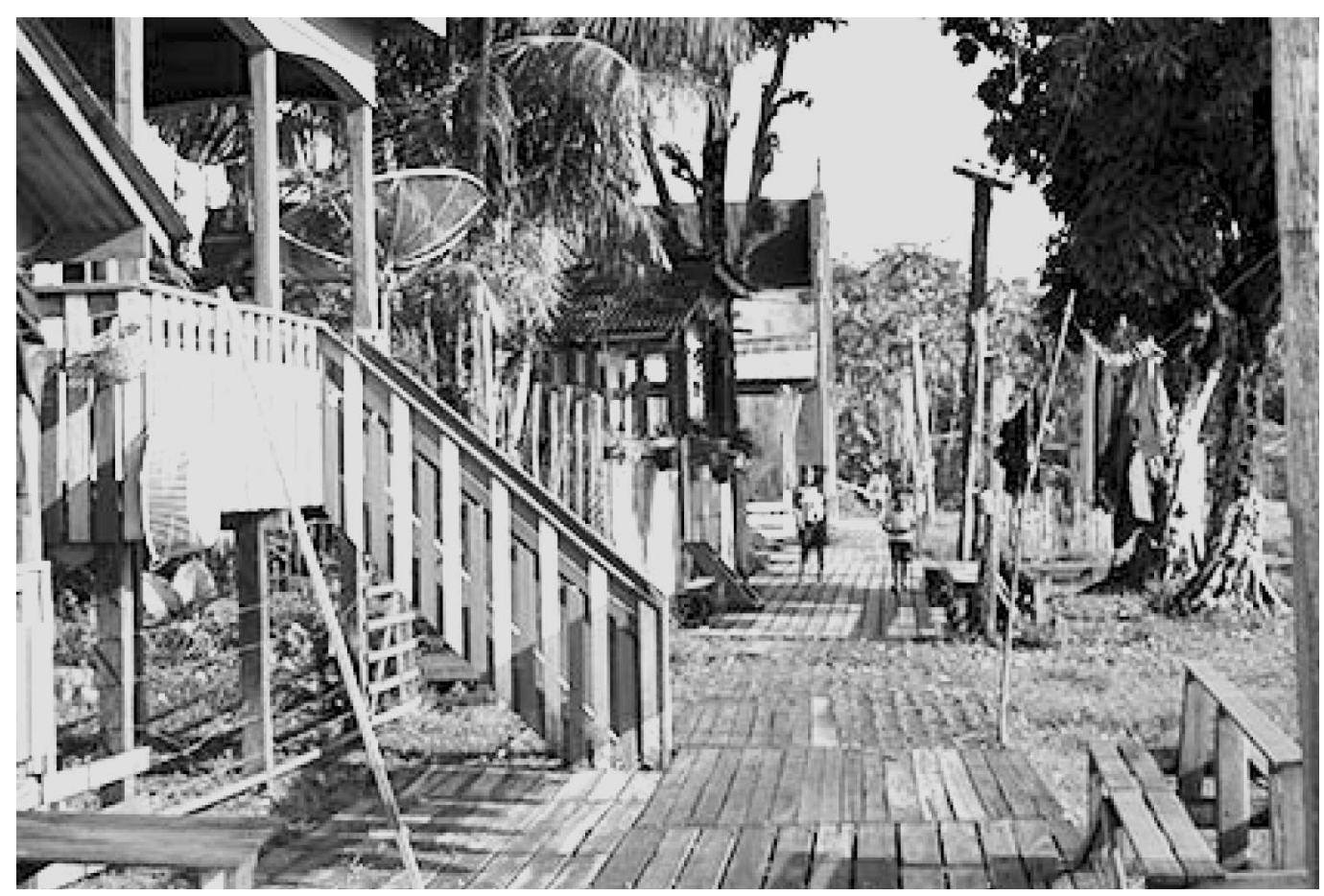

Figura 2 - Comunidade de Antônio Lemos

Foto: Valdomiro Lourenço Nachornik

Os rondonistas realizaram, ainda, muitas atividades lúdicas e recreativas com as crianças como pintura de rosto, jogos, balões, contação de estórias, desenhos para colorir, massinha de modelar etc. As atividades educacionais abrangiam todas as faixas etárias, através de distribuição de folhetos e folders, palestras em grupo e orientações individuais sobre Doenças Sexualmente Transmissíveis (DST) e distribuição de preservativos, saúde bucal com a utilização do escovódromo e a distribuição de kits odontológicos, higiene, sanitização da água e distribuição de hipoclorito de sódio, nutrição, diabetes, violência contra a mulher etc. Os rondonistas revezavam-se entre as atividades assistenciais, recreativas e educativas.

Paralelamente aos atendimentos de saúde, os profissionais do INSS e da Capitania dos Portos realizavam suas abordagens específicas, como os Cursos de Formação de Aquaviários, inspeção de embarcações, palestras sobre segurança na navegação, cobertura de eixos de embarcações para evitar acidentes por escalpelamento, licenças para tratamento de saúde, licenças-maternidade dentre outros atendimentos.

Segundo o levantamento realizado pela Marinha, em nove dias de ações conjuntas, milhares de ribeirinhos foram atendidos, através de consultas, realização de exames e procedimentos. Os 
resultados obtidos foram: 1.421 atendimentos médicos; 800 atendimentos odontológicos; 148 exames laboratoriais realizados; 94 mamografias; 24.683 medicamentos distribuídos; 102 palestras sobre prevenção de DST; 3.687 atendimentos realizados pelo INSS; 142 embarcações abordadas; 07 embarcações apreendidas; 355 ouvintes em palestras de Reciclagem; 73 novos aquaviários formados em Cursos de Formação e 62 coberturas de eixo instaladas em embarcações (MARINHA DO BRASIL, 2014b).

O Navio permaneceu fundeado em Cutijuba para o encerramento das atividades e, ainda no dia 28, suspendeu às $19 \mathrm{~h}$, iniciando-se a viagem de retorno a Belém, chegando ao destino no dia 30, às 10h, atracando novamente na Base Naval de Val de Cães.

Ainda no dia 30, oportunizou-se aos rondonistas conhecer um pouco da cidade de Belém, como a feira do Ver-o-Peso, a Estação das Docas e o Forte do Presépio. Puderam também experimentar sucos de frutas e sorvetes com sabores típicos da região e adquirir alguns objetos artesanais.

$\mathrm{Na}$ madrugada do dia 31, iniciou-se o retorno dos integrantes do Projeto Rondon para suas localidades de origem.

\section{Considerações finais}

Para os rondonistas, foi uma experiência inesquecível e uma vivência extremamente gratificante poder contribuir com o atendimento de aproximadamente 2.221 ribeirinhos, auxiliar na distribuição de 24.683 medicamentos, colaborar com a realização de 148 exames laboratoriais e realizar 102 palestras sobre DST. A viagem propiciou também a convivência com os militares da marinha em torno de uma missão comum que era a ACiSo. Para além dos atendimentos de saúde a equipe se deparou com a extrema carência dessa população no tocante a atenção pessoal. Prova disso, eram os sorrisos sinceros recebidos, o forte aperto de mão ou simplesmente um olhar carinhoso de cada uma daquelas pessoas. Com certeza, mais do que prestar os serviços e ensinar, muito se aprendeu e, assim como aqueles inúmeros e caudalosos rios paraenses se renovam constantemente, certamente, os rondonistas não retornaram as mesmas pessoas de antes, mas melhores, mais cidadãs e conscientes do seu papel na sociedade. No relato final se observou que os rondonistas passaram a valorizar ainda mais a oportunidade de cursar uma universidade seja pública ou particular, tendo em vista que a vivência com cada um daqueles brasileiros contribui indiretamente para uma melhor formação profissional de cada integrante do Projeto Rondon.

\section{Fontes de financiamento}

As instituições que participaram do financiamento do projeto foram o Ministério da Defesa (MD) (coordenação e passagens aéreas) através da Marinha do Brasil (execução) e a Universidade Federal de Viçosa (UFV) através do Núcleo de Apoio a Programas e Projetos de Extensão (NAPE) da Pró-reitoria de Extensão e Cultura (PEC), que viabilizou uma ajuda de custo para a rondonista, representante da universidade.

\section{Referências bibliográficas}

BRASIL. Governo Federal. Grupo Executivo Interministerial. Plano de Desenvolvimento Territorial Sustentável para o Arquipélago do Marajó: resumo executivo da versão preliminar para discussão nas consultas públicas / Governo Federal, Grupo Executivo Interministerial. Brasília: Ministério da Saúde, 2007. 24 p. il.

FUNDO VALE. Instituto Peabiru. Diagnóstico Socioeconômico, Ambiental e Cultural do Arquipélago do Marajó. Vivamarajó, Belém: Versão preliminar, 2011.

IBGE. Instituto Brasileiro de Geografia e Estatística. 2010. Disponível em: <http:// www.cidades.ibge.gov.br/xtras/perfil.php?lang=\&codmun=150580>. Acesso em: 3 ago. 2014.

MARINHA DO BRASIL. Marinha realiza Ações Cívico-Sociais com integrantes do Projeto "Rondon" em regiões do Pará. Disponível em: <https://www.marinha.mil.br/noticias/marinha-realiza\% C $3 \%$ A 7 \% C $3 \%$ B 5 es-c \% C $3 \%$ A Dvico-sociais-com-integrantes-do-projeto$\% \mathrm{E} 2 \% 80 \% 9$ Crondon\%E2\%80\%9D-em-regi\%C3\%B5es-do-par\%C3\%A1>. Acesso em: 3 ago. 2014a. 
Militares do Navio-Auxiliar "Pará" realizam ACISO nas comunidades de Portel (PA). Disponível em: $<$ http:// www.marinha.mil.br/noticias/militares-do-navio-auxiliar\% $2 \%$ 80\%9Cpar\%C3\%A1\%E2\%80\%9D-realizam-aciso-nas-comunidades-de-portel-pa>. Acesso em: 3 ago. 2014b.

Navio-Auxiliar "Pará" distribui donativos para comunidades ribeirinhas no Pará. Disponível em: $<$ https://www.marinha.mil.br/noticias/navio-auxiliar-\%E2\%80\%9Cpar\%C3\%A1\%E2\%80\%9Ddistribui-donativos-para-comunidades-ribeirinhas-no-par\%C3\%A1?>. Acesso em: 4 ago. 2014c.

\footnotetext{
${ }^{3}$ Portal G1. Marinha leva ações de saúde a municípios no Marajó, no Pará. Disponível em: <http://g1.globo.com/pa/para/noticia/2014/07/marinha-leva-acoes-desaude-municipios-no-marajo-no-para.html>. Acesso em: 4 ago. 2014.

${ }^{4}$ Rede Globo. Programa "Bom Dia Brasil". Mutirão atende mulheres no interior do Pará que nunca tinham feito mamografia. Disponível em: <http://globotv.globo.com/ rede-globo/bom-dia-brasil/v/mutirao-atende-mulheres-no-interior-do-para-que-nunca-tinham-feito-mamografia/3528059/>. Acesso em: 4 ago. 2014.

${ }^{5}$ Rede Globo. Programa "Como será?" Navios da Marinha levam serviços de saúde a comunidades ribeirinhas. Disponível em: <http://redeglobo.globo.com/como-sera/ noticia/2014/10/navios-da-marinha-levam-servicos-de-saude-comunidades-ribeirinhas.html>. Acesso em: 7 out. 2014.
} 